\title{
Sous la direction de Guillaume Herzberg: Avant bras post traumatique Arthroscopie-arthroplasties
}

\author{
Sauramps médical 2009, 66.50 €, ISBN: 978-2-84023-639-9, Language: French
}

\author{
Alain Graftiaux
}

Received: 20 December 2010/Accepted: 21 December 2010/Published online: 19 January 2011

(c) Springer-Verlag 2011

This book treats forearm as an anatomical unit including, at the same time, the higher and lower radio-ulnar articulations and also of the interosseous membrane. This rather new concept makes it possible thanks to progress of the imagery to better understand the traumatisms and thus to avoid the after-effects and when they are there better to treat them.

The book by several authors written is divided into several great chapters. First chapter studies the fractures of the head of radius and the various ways of treating them.
The second part treats fractures of Monteggia and Galeazzi and the third of the vicious cal (malunions) and synostoses.

This book thus makes it possible to evaluate lesions well which are sometimes difficult to apprehend. It will particularly interest all the surgeons interested by traumatology and its after-effects.

Conflict of interest No funds were received in support of this study. 